\title{
Electrochemical Sandwich Immunoassay for the Ultrasensitive Detection of Human MUC1 Cancer Biomarker
}

\author{
Zahra Taleat, ${ }^{1,2}$ Cecilia Cristea, ${ }^{1}$ Giovanna Marrazza, ${ }^{3}$ and Robert Săndulescu ${ }^{1}$ \\ ${ }^{1}$ Analytical Chemistry Department, Faculty of Pharmacy, Iuliu Haţieganu University of Medicine and Pharmacy, \\ 4 Pasteur Street, 400021 Cluj-Napoca, Romania \\ ${ }^{2}$ Department of Chemistry, Faculty of Science, Yazd University, 89195-741 Yazd, Iran \\ ${ }^{3}$ Department of Chemistry Ugo Schiff, University of Science Florence, P.zza S.Marco, 4, 50121 Florence, Italy
}

Correspondence should be addressed to Cecilia Cristea; ccristea@umfcluj.ro

Received 12 September 2013; Revised 14 November 2013; Accepted 18 November 2013

Academic Editor: Sergio Ferro

Copyright (c) 2013 Zahra Taleat et al. This is an open access article distributed under the Creative Commons Attribution License, which permits unrestricted use, distribution, and reproduction in any medium, provided the original work is properly cited.

\begin{abstract}
A new electrochemical sandwich immunoassay for the ultrasensitive detection of human MUC1 cancer biomarker using protein G-functionalized magnetic beads (MBs) and graphite-based screen-printed electrodes (SPEs) was developed. Magnetic beads were employed as the platforms for the immobilization and immunoreaction process. A pair of primary and secondary antibodies was used to capture the MUCl protein. After labeling with a third antibody conjugated with horseradish peroxidase (HRP), the resulting conjugate was trapped at the surface of the graphite-based SPEs and MUC1 determination was carried out by differential pulse voltammetry (DPV) at $0.4 \mathrm{~V}$ upon $\mathrm{H}_{2} \mathrm{O}_{2}$ addition using acetaminophen (APAP) as the redox mediator. A linear relationship was obtained for the detection of human $\mathrm{MUCl}$ over a range of $0-25 \mathrm{ppb}$ with the lowest detection limit of $1.34 \mathrm{ppb}$ when HRP was applied as a label. Preliminary experiments were performed using disposable electrochemical sensors in order to optimize some parameters (i.e., incubation times, concentrations, and blocking agent).
\end{abstract}

\section{Introduction}

MUCl mucin is an integral membrane glycoprotein expressed by most if not all "wet" epithelia, such as on bladder, breast, gastric, pancreas, ovary, and respiratory tract epithelium, with a molecular weight varying between 250 and $1000 \mathrm{kD}$ [1].

In normal secretory epithelial cells, $\mathrm{MUC1}$ is expressed at the apical plasma membrane. However, following malignant transformation, MUC1 may be expressed at high levels on the entire membrane surface as well as in the cytoplasm. In addition to the altered cellular localization, changes in glycosylation may occur during malignant transformation $[2,3]$. Although the numbers of glycosidic links are increased, the carbohydrate chains are generally shorter [4]. The reduced glycosylation reveals protein epitopes, making MUC1 more accessible to specific antibodies. Thus, overexpression and altered glycosylation allow MUC1 to be used as a cancer marker.

Widespread use of tumor markers in healthcare will ultimately depend upon the detection of many tumor markers with high selectivity and sensitivity. This goal has not been obtained with conventional methods which have poor precision or are experiencing difficulties in realizing automatization [5]. Recently, electrochemical immunosensors have received considerable attention for the detection of tumor markers due to their high sensitivity and easy miniaturization $[6,7]$.

Most immunoassay techniques are based on the separation of free and bound immunospecies. In the electrochemical immunosensors, one of the immunoagents (antigen or antibody) is immobilized on a solid carrier, capturing/binding the analyte to form an immunocomplex. As an ideal platform candidate, magnetic beads (MBs) allow for quick and efficient purification and concentration from crude samples, thereby eliminating the need for most of the pretreatment steps, as well as the matrix effect from the samples. Additionally, MBs can provide a low detection limit since MBs have large surface area to immobilize biomolecules. More importantly, MBs allow a simple manipulation, the immunocomplex being first formed on the beads surface and 
then, in a second step, immobilized on the surface of the electrode [8], effectively reducing in this way the complexity and time required for sensing application [9-15].

Quantification of bound immunoagents is conducted by using labels covalently bound to the immunoagent with specific properties suitable for detection. As a result, the final stage of immunoassay is in fact the quantitative detection of the label. Enzymes are the most frequently used labels linked to the antigen or to the antibody to visualize the binding event [16]. However, direct electrical communication between the redox sites of enzymes and the electrode usually is not possible because the redox sites of the enzymes are located deep inside the protein shell [17]. Therefore, redox mediators are required to facilitate the electron transfer between enzyme and electrode. Indeed, in order to achieve high sensitivity, the amount of mediator, as well as that of the enzyme, needs to be sufficiently high. Horseradish peroxidase (HRP), an enzyme which catalyzes the oxidation of a wide variety of organic and inorganic substrates in the presence of $\mathrm{H}_{2} \mathrm{O}_{2}$, was also used [18].

One sandwich immunoassay (three-layer format) was employed to detect MUC1 with horseradish peroxidase-conjugated Ab3, as a label. The determination of MUC1 was established by DPV upon $\mathrm{H}_{2} \mathrm{O}_{2}$ additions to record the reduction current response of acetaminophen as the redox mediator in the case of HRP-labeled immunoassay. These immunosensors displayed high sensitivity and a low detection limit. To our knowledge, the use of MBs and graphite SPEs for the construction of an immunosensor in a sandwich format for the detection of $\mathrm{MUC1}$ has not been reported so far, so it may have potential clinical application in the future.

\section{Materials and Methods}

2.1. Reagents and Apparatus. Dynabeads protein G-coated magnetic beads (superparamagnetic beads with the diameter of $2.8 \mu \mathrm{m}$ ) were purchased from Invitrogen. MUC1 monoclonal mouse antibody (Ab1), MUC1 recombinant protein (Ag), and MUC1 polyclonal rabbit antibody (Ab2) were provided by Novus Biological. Polyclonal goat anti-rabbit IgG labeled with HRP (HRP-Ab3) was obtained from DakoCytomation. Bovine serum albumin (BSA), sodium chloride, potassium chloride, magnesium chloride, and polyoxyethylene sorbitan monolaurate (Tween 20) were purchased from Sigma-Aldrich. Disodium hydrogen phosphate, sodium dihydrogen phosphate, potassium ferrocyanide $\left(\mathrm{K}_{4}\left[\mathrm{Fe}(\mathrm{CN})_{6}\right]\right)$, potassium ferricyanide $\left(\mathrm{K}_{3}\left[\mathrm{Fe}(\mathrm{CN})_{6}\right]\right)$, hydrogen peroxide, and tris(hydroxymethyl)aminomethane (TRIS) were obtained from Merck. All the solutions were prepared using Milli$\mathrm{Q}$ grade water.

The buffers used in the experiments are PBS ( $\mathrm{pH} 7.4)$ : phosphate buffered saline, $\mathrm{pH} 7.4$; PBS-T ( $\mathrm{pH}$ 7.4): phosphate buffered saline, $\mathrm{pH} 7.4$ with $0.005 \% \mathrm{w} / \mathrm{w}$ Tween 20; PBS ( $\mathrm{pH}$ 7.2): phosphate buffered saline, $\mathrm{pH}$ 7.2; PBS-T ( $\mathrm{pH} 7.2$ ): phosphate buffered saline, $\mathrm{pH} 7.2$ with $0.005 \%$ w/w Tween 20; TRIS: $50 \mathrm{mM}$ TRIS buffer, $10 \mathrm{mM} \mathrm{NaCl}, \mathrm{pH}$ 8; TRIS-T: TRIS $20 \mathrm{mM}, 150 \mathrm{mM} \mathrm{NaCl}, 0.1 \%$ BSA with $0.005 \%$ w/w Tween 20 , $\mathrm{pH} 7.4$.
Electrochemical experiments were performed with an Autolab PGSTAT 30 digital potentiostat/galvanostat with a GPES 4.9 software package (Eco Chemie, the Netherlands). Graphite-based screen-printed electrodes were produced by a DEK 248 screen printing machine at laboratory or were provided by DropSens (Spain). They are disposable threeelectrode cells consisting of a graphite working electrode, a silver pseudo-reference electrode, and a graphite counter electrode. All the measurements were carried out at room temperature $\left(25^{\circ} \mathrm{C}\right)$.

The electrochemical impedance spectroscopy (EIS) measurements were carried out in the presence of $10 \mathrm{mM}$ $\left[\mathrm{Fe}(\mathrm{CN})_{6}\right]^{3 / 4-}$ redox probe in PBS ( $\mathrm{pH}$ 7.4). The impedance was measured in a frequency range from $100 \mathrm{mHz}$ to $100 \mathrm{KHz}$ at a dc potential of $+0.13 \mathrm{~V}$, the formal potential of the $\left[\mathrm{Fe}(\mathrm{CN})_{6}\right]^{3 / 4-}$ redox probe. Experimental spectra, presented in the form of complex plane diagrams (i.e., Nyquist plots), were fitted with proper equivalent circuits using the facilities of the FRA2 software 4.9 (Eco Chemie). Differential pulse parameters are modulation time, $0.05 \mathrm{~s}$; interval time, $0.15 \mathrm{~s}$; step potential, $5 \mathrm{mV}$; modulation amplitude, $70 \mathrm{mV}$; potential scan, from +0.2 to $+0.8 \mathrm{~V}$.

\subsection{Preparation of the Immunosensor}

2.2.1. Immobilization of $A b 1$ and Blocking Agent onto the $M B s$. For the fabrication of the sandwich immunosensor, illustrated in Figure 1, $100 \mu \mathrm{L}$ of the MBs from stock solution was placed in a vial and separated from the suspension media with a magnetic concentrator (MPC-S, Invitrogen). Subsequently, the MBs were washed three times with PBS$\mathrm{T}$ buffer ( $\mathrm{pH}$ 7.4). After removing the solution, MBs were suspended in $200 \mu \mathrm{L}$ of $50 \mathrm{ppm}$ Ab1 solution prepared in PBS buffer ( $\mathrm{pH}$ 7.4) and incubated for two hours in the rotating stand at the room temperature.

To minimize the effect of nonspecific binding on detection, the Abl functionalized MBs were washed three times with PBS-T buffer ( $\mathrm{pH}$ 7.2) solution and then the free sites on the surface of MBs were blocked by using 5\% BSA as blocking agent were prepared in PBS buffer. MBs were then washed three times with $500 \mu \mathrm{L}$ of PBS-T buffer ( $\mathrm{pH} 7.4$ ), suspended in $500 \mu \mathrm{L}$ of $\mathrm{PBS}$ buffer ( $\mathrm{pH} 7.4$ ), and stored at $4^{\circ} \mathrm{C}$.

2.2.2. Binding of the MUC1 Protein. $50 \mu \mathrm{L}$ of the Ab1-BSA functionalized MBs suspension was mixed, after the removal of the supernatant, with $500 \mu \mathrm{L}$ of MUC1 protein solution in TRIS of different concentrations, between 0 and $25 \mathrm{ppb}$, for 90 minutes of incubation time at room temperature. Unbound antigens in excess were removed by washing with TRIS-T buffer (pH 7.4).

2.2.3. Reaction with Ab2 and HRP Conjugated Ab3. The Ab1BSA-Ag modified MBs were mixed with $200 \mu \mathrm{L}$ of 5 ppm Ab2 solution prepared in PBS buffer ( $\mathrm{pH} 7.4$ ) for 90 min. Finally, after rinsing with TRIS-T buffer ( $\mathrm{pH} 7.4$ ), the MBs were incubated with $50 \mu \mathrm{L}$ of a solution containing $1.5 \mathrm{mg} / \mathrm{L}$ of the HRP-Ab3 in TRIS-T buffer. After $30 \mathrm{~min}$, MBs were washed three times and suspended in $50 \mu \mathrm{L}$ of the same buffer. 


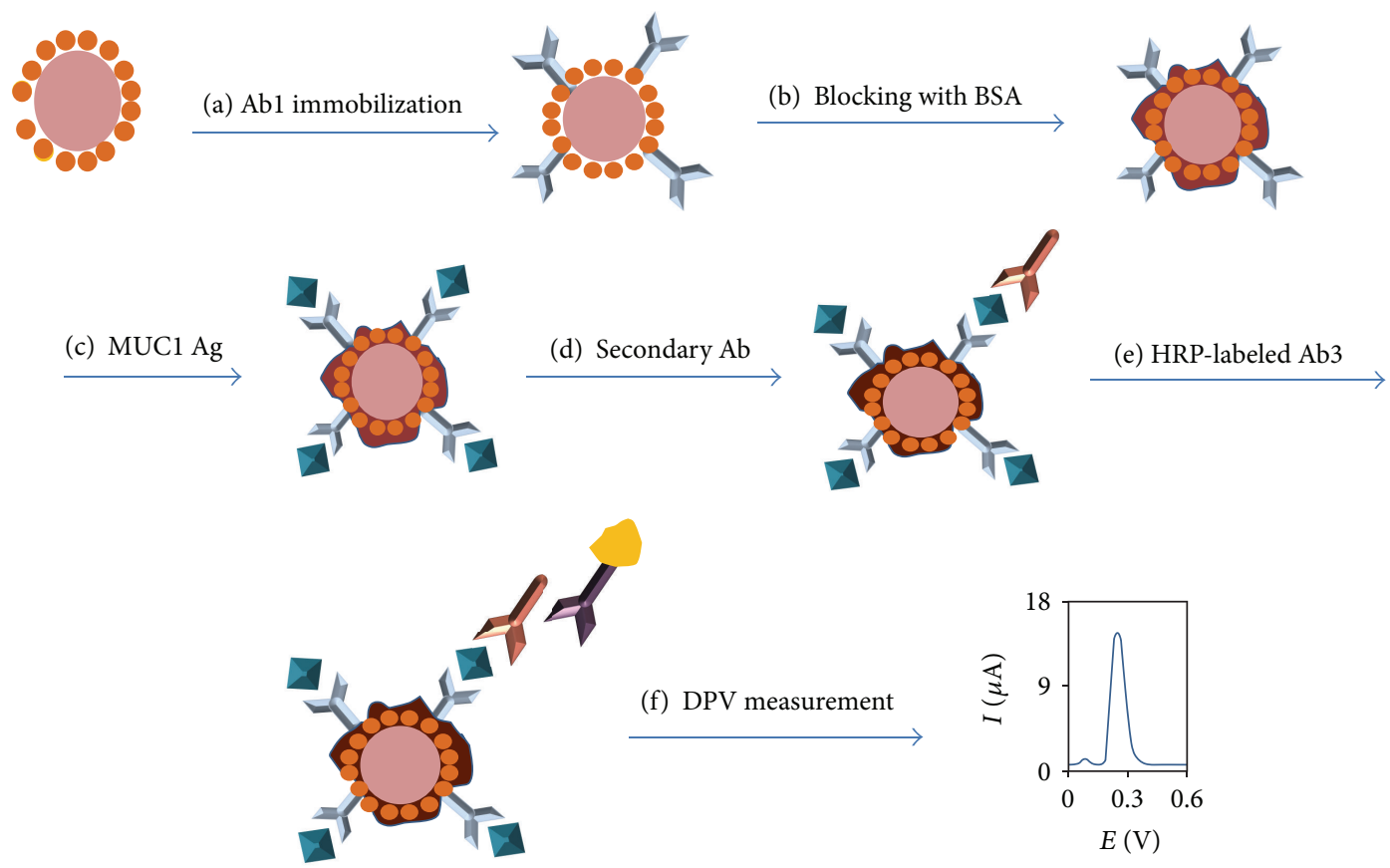

FIGURE 1: Sandwich immunosensor preparation for MUC1 detection: (a) primary antibody attachment on MBs surface; (b) MBs free bindingsites blocking using BSA; (c) incubation with MUC1 antigen solutions and Ab1/MUC1 Ag complex formation on the MBs; (d) reaction with Ab2, (e) incubation with Ab3 labeled with HRP; (f) DPV measurements of MBs-bound MUC1 in presence of acetaminophen/ $\mathrm{H}_{2} \mathrm{O}_{2}$ [19].

\section{Results and Discussion}

The stepwise procedure of the sandwich immunosensor development is shown in Figure 1. In a typical experiment, Abl was immobilized on the surface of modified protein $G$ magnetic beads (a), and then free sites were blocked with $5 \%$ blocking agent solution (b) followed by the reaction with MUC 1 antigen (c) and the reaction with the second antibody Ab2 (d).

After introducing Ab3 labeled with $\mathrm{HRP}$ (e) on MBs, DPV measurements were recorded 5 minutes after the deposition of $10 \mu \mathrm{L}$ modified beads onto graphite-based SPEs and the covering of the electrode's surface with substrate solution (f). The substrate solution is represented by $40 \mu \mathrm{L}$ of $\mathrm{H}_{2} \mathrm{O}_{2} 4 \mathrm{mM}$ $+10 \mu \mathrm{L}$ of PBS containing $2 \mathrm{mM}$ of acetaminophen.

Preliminary experiments were performed using modified MB on disposable screen-printed electrodes in order to optimize some analytical parameters in terms of incubation time, the type of blocking agent, and antibodies concentration.

\subsection{Optimization of Immobilization Conditions}

3.1.1. Incubation Time and Concentration. The incubation time and concentrations required for antibodies immobilization and the antigen-antibody immunoreaction are important parameters that determine the performance of an immunosensor. To optimize the time required for the complete immunoreaction to take place, modified MBs were incubated in $5 \mathrm{ppb}$ of $\mathrm{MUC1}$ protein solution for various time periods for Ab1, MUC1 Ag, and Ab2. DPV measurements were then performed using these incubated MBs on graphite-based SPEs. Only functionalized MBs incubated for $120 \mathrm{~min}$ for Ab1, $90 \mathrm{~min}$ for MUC1 Ag, and $90 \mathrm{~min}$ for Ab2 (Figure 2(a)) exhibited a stable response indicating the complete interaction between them.

After optimizing the incubation times used in different steps in the construction of the immunosensor, the concentration of $\mathrm{Ab} 1$ and $\mathrm{Ab} 2$ had to be optimized as well (data not shown). In order to optimize the primary antibody concentration, the MBs were functionalized with $10 \mathrm{ppm}$, $50 \mathrm{ppm}$, and $100 \mathrm{ppm}$ primary antibodies. An increase of the signal was observed for the concentration of the Ab1 of $50 \mathrm{ppm}$, respect to $10 \mathrm{ppm}$. For concentrations higher than $50 \mathrm{ppm}$, considerable variation of signal was not observed, indicating that after this concentration a steady state is achieved. The concentration of $50 \mathrm{ppm}$ primary solution was therefore chosen for further experiments.

For the optimization of Ab2 concentration, $5 \mathrm{ppm}, 10 \mathrm{ppm}$ and $20 \mathrm{ppm}$ of antibody solution were used. Between the signals obtained for 5 and $10 \mathrm{ppm}$ of $\mathrm{Ab} 2$ concentration, a significant difference was not found. For concentrations higher than $10 \mathrm{ppm}$, the secondary antibody binds probably directly on the magnetic beads, leading to a nonspecific adsorption; therefore, $5 \mathrm{ppm}$ was assigned as the optimized value for further analysis.

3.1.2. Blocking Agent. The type and incubation time of the blocking agent on the immunosensor response were also investigated (Figure 2(b)). Milk powder (casein) and BSA were used as blocking agents with different incubation times. The Abl functionalized MBs were incubated with both milk powder $5 \%$ and BSA 5\% in PBS buffer ( $\mathrm{pH} 7.2)$ for two hours 


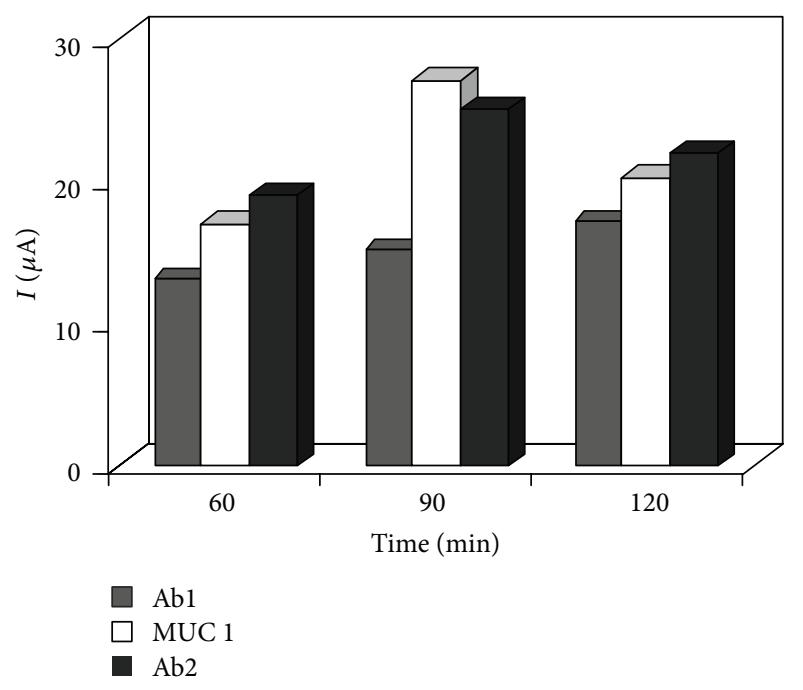

(a)

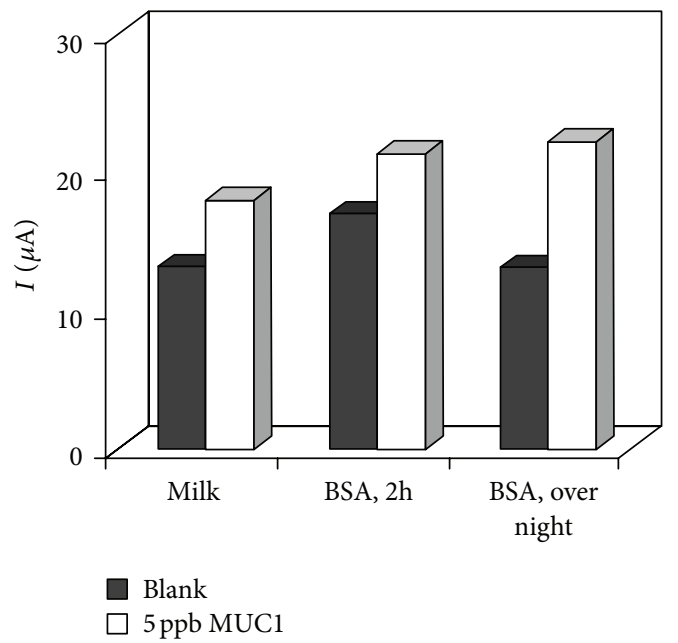

(b)

FIgURE 2: Optimization diagram for Ab1, MUC1 antigen, and Ab2 incubation times (a) and for blocking agent type and incubation time (b).

and overnight, respectively, and the experiments were carried out as the above described procedure. Overnight incubation time with BSA 5\% showed the best results.

3.2. Impedance Characterization of Immunosensor. Compared with other electrochemical methods, the impedance technique has the advantage that the system is investigated under stationary conditions as opposed to the wide potential window used in CVs [20]. The features of HRP-MBsbased immunosensor were investigated by EIS in $10 \mathrm{mM}$ $\left[\mathrm{Fe}(\mathrm{CN})_{6}\right]^{3 / 4-}$ prepared in PBS buffer ( $\mathrm{pH}$ 7.4) step by step (Figure 3 ). It could be seen that the diameter of the semicircle in the impedance spectrum of bare graphite SPEs (Figure 3, curve a) increased after the immobilization of Abl and BSA (Figure 3, curve b). A change in impedance was observed after incubation with MUC1 antigen and Ab2 (Figure 3, curve c). The reasonable explanation is the electrostatic

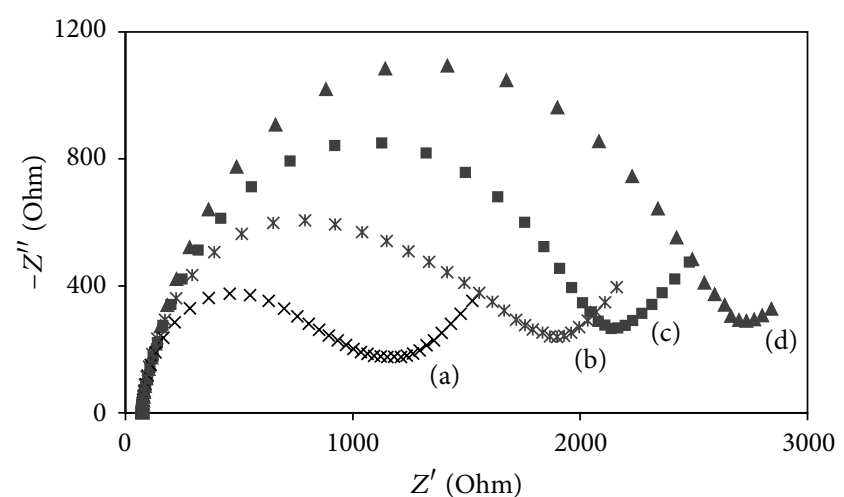

FIGURE 3: Nyquist diagram for the EIS measurements in $10 \mathrm{mM}$ $\left[\mathrm{Fe}(\mathrm{CN})_{6}\right]^{3 / 4-}$ in PBS $(\mathrm{pH} 7.4)$ at $+0.13 \mathrm{~V}$ bias potential for the bare graphite SPE (a); after the Ab1 immobilization (b); the immunoreactions with MUC1 protein and Ab2 (c); the binding to HRP-labeled $\mathrm{Ab} 3(\mathrm{~d})$.

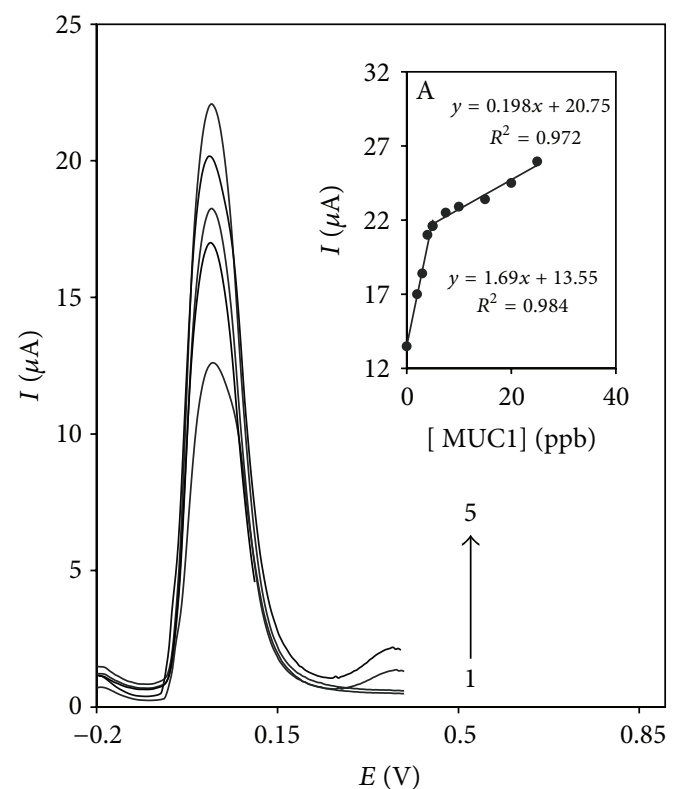

FIGURE 4: Differential pulse voltammograms of $2 \mathrm{mM}$ acetaminophen in $0.1 \mathrm{M} \mathrm{PBS}$ ( $\mathrm{pH}$ 7.4) containing $4 \mathrm{mM} \mathrm{H}_{2} \mathrm{O}_{2}$ registered with Ab1-BSA/Ag/Ab2/Ab3 modified MBs for different concentrations of MUC1 protein (1-5 correspond to $0,2,3,4$, and $5 \mathrm{ppb}$ of MUC1).

repulsion between the proteins and $\left[\mathrm{Fe}(\mathrm{CN})_{6}\right]^{3 / 4-}$ anion, which indicates that the antibodies and MUCl antigen have been successfully immobilized on MBs and obstructed electron transfer. When HRP-Ab3 was introduced, the interfacial resistance increased more, demonstrating that the sensing interface is constructed successfully (Figure 3, curve d).

3.3. Analytical Calibration. The sandwich immunoassay was used for quantitative analysis of MUCl concentrations. The electrochemical measurements were carried out under optimum conditions using graphite-based SPE and the results are shown in Figure 4. First, $10 \mu \mathrm{L}$ of modified MBs was deposited 
TABLE 1: Determination of MUC1 in human serum samples.

\begin{tabular}{lccc}
\hline Sample type & Code & $\begin{array}{c}\text { Immunosensor } \\
(\mathrm{ppb})\end{array}$ & $\mathrm{RSD}(n=3)$ \\
\hline \multirow{3}{*}{ Breast cancer } & 233 & 4 & 4.80 \\
& 235 & 3.8 & 3.92 \\
Ovarian cancer & 38 & 10 & 3.76 \\
\hline
\end{tabular}

on the working electrode surface and the stocking buffer was carefully removed with the aid of a micropipette. Then, the graphite-based SPE was covered with $40 \mu \mathrm{L}$ of $4 \mathrm{mM}$ $\mathrm{H}_{2} \mathrm{O}_{2}$ prepared in PBS and $10 \mu \mathrm{L}$ of PBS containing $2 \mathrm{mM}$ of acetaminophen was added. After $5 \mathrm{~min}$, DPV measurements were recorded for different concentrations of MUC1 protein: $0,2,3,4,5,7.5,10,15,20$, and $25 \mathrm{ppb}$. The limit of detection (LOD) was defined as the lowest concentration of biomarker producing a peak current 3 times higher than the standard deviation of the peak current in the absence of MUC1 under identical conditions. A sigmoid curve for the current variation was observed over the range $0-25 \mathrm{ppb}$ of MUC1 with LOD $1.34 \mathrm{ppb}$ (Figure 4, inset A). Inset A shows calibration plot of the DPV signal against the MUC1 protein concentration with two linear domains.

3.4. MUC1 Analysis in Human Serum Samples. Direct determination of serum MUC1 level is very important in the early detection of breast and ovarian cancer. The MUCl contents in unknown real human serum samples were quantified with the designed immunosensor. All experimental results are given in Table 1.

The samples were obtained from patients suffering from breast or ovarian cancer, filtered, diluted $1: 200$, and assayed as in the procedure previously described. The standard addition method was used in order to quantify the amount of the tumor markers in the samples. The limit of detection in serum was calculated interpolating the mean current of the blank plus three times its standard deviation in the linear equation.

Experimental results revealed that the proposed immunosensor showed good sensitivity with wider linear range.

\section{Conclusions}

In summary, a magnetic beads-based electrochemical immunosensor is described as a device for the quantitative detection of human MUC1 antigen. During incubation, primary antibodies were bound to the functionalized MBs via their Fc regions and successively attached to the antigen and secondary antibody. This paper provides new perspectives on using HRP as the biocatalyst in the detection of MUC1 cancer biomarker in the presence of hydrogen peroxide on GSP electrodes. The present method could be applied for the detection of MUC1 in real samples of ovarian and breast cancer.

\section{Conflict of Interests}

The authors declare that there is no conflict of interests regarding the publication of this paper.

\section{Acknowledgment}

The authors are grateful for the financial support from the Romanian National Authority for Scientific Research, CNCSUEFISCDI for the Project PN-II-ID-PCE-2011-3-0355.

\section{References}

[1] R. Graves, J. Hilgers, H. Fritsche, D. Hayes, and J. F. R. Robertson, "MUC-1 mucin assays for monitoring therapy in metastatic breast cancer," The Breast, vol. 7, no. 4, pp. 181-186, 1998.

[2] C. L. Hattrup and S. J. Gendler, "Structure and function of the cell surface (tethered) mucins," Annual Review of Physiology, vol. 70, pp. 431-457, 2008.

[3] D. W. Kufe, "Mucins in cancer: function, prognosis and therapy," Nature Reviews Cancer, vol. 9, no. 12, pp. 874-885, 2009.

[4] J. M. Burchell, A. Mungul, and J. Taylor-Papadimitriou, "O-linked glycosylation in the mammary gland: changes that occur during malignancy," Journal of Mammary Gland Biology and Neoplasia, vol. 6, no. 3, pp. 355-364, 2001.

[5] H. Chen, C. Jiang, C. Yu, S. Zhang, B. Liu, and J. Kong, "Protein chips and nanomaterials for application in tumor marker immunoassays," Biosensors and Bioelectronics, vol. 24, no. 12, pp. 3399-3411, 2009.

[6] J. Wu, Z. Fu, F. Yan, and H. Ju, "Biomedical and clinical applications of immunoassays and immunosensors for tumor markers," Trends in Analytical Chemistry, vol. 26, no. 7, pp. 679-688, 2007.

[7] J. Lin and H. Ju, "Electrochemical and chemiluminescent immunosensors for tumor markers," Biosensors and Bioelectronics, vol. 20, no. 8, pp. 1461-1470, 2005.

[8] E. Paleček and M. Fojta, "Magnetic beads as versatile tools for electrochemical DNA and protein biosensing," Talanta, vol. 74, no. 3, pp. 276-290, 2007.

[9] M. Eguílaz, M. Moreno-Guzmán, S. Campuzano, A. GonzálezCortés, P. Yáñez-Sedeño, and J. M. Pingarrón, "An electrochemical immunosensor for testosterone using functionalized magnetic beads and screen-printed carbon electrodes," Biosensors and Bioelectronics, vol. 26, no. 2, pp. 517-522, 2010.

[10] A. Hayat, L. Barthelmebs, and J.-L. Marty, "Enzyme-linked immunosensor based on super paramagnetic nanobeads for easy and rapid detection of okadaic acid," Analytica Chimica Acta, vol. 690, no. 2, pp. 248-252, 2011.

[11] M. Moreno-Guzmán, A. González-Cortés, P. Yáñez-Sedeño, and J. M. Pingarrón, "A disposable electrochemical immunosensor for prolactin involving affinity reaction on streptavidinfunctionalized magnetic particles," Analytica Chimica Acta, vol. 692, no. 1-2, pp. 125-130, 2011.

[12] S. Campuzano, B. E.-F. de Ávila, J. Yuste et al., "Disposable amperometric magnetoimmunosensors for the specific detection of Streptococcus pneumoniae," Biosensors and Bioelectronics, vol. 26, no. 4, pp. 1225-1230, 2010.

[13] M. Hervás, M. Á. López, and A. Escarpa, "Electrochemical immunoassay using magnetic beads for the determination of zearalenone in baby food: an anticipated analytical tool for food safety," Analytica Chimica Acta, vol. 653, no. 2, pp. 167-172, 2009. 
[14] D. Du, J. Wang, L. Wang et al., "Magnetic electrochemical sensing platform for biomonitoring of exposure to organophosphorus pesticides and nerve agents based on simultaneous measurement of total enzyme amount and enzyme activity," Analytical Chemistry, vol. 83, no. 10, pp. 3770-3777, 2011.

[15] I. Y. Goon, L. M. H. Lai, M. Lim, R. Amal, and J. J. Gooding, "Dispersible electrodes: a solution to slow response times of sensitive sensors," Chemical Communications, vol. 46, no. 46, pp. 8821-8823, 2010.

[16] M. Diaz-Gonzalez, M. B. Gonzalez-Garcia, and A. CostaGarcia, "Recent advances in electrochemichal enzyme immunoassays," Electroanalysis, vol. 17, no. 21, pp. 1901-1918, 2005.

[17] C. Ruan, F. Yang, C. Lei, and J. Deng, "Thionine covalently tethered to multilayer horseradish peroxidase in a self-assembled monolayer as an electron-transfer mediator," Analytical Chemistry, vol. 70, no. 9, pp. 1721-1725, 1998.

[18] X.-M. Li, X.-Y. Yang, and S.-S. Zhang, "Electrochemical enzyme immunoassay using model labels," Trends in Analytical Chemistry, vol. 27, no. 6, pp. 543-553, 2008.

[19] I. Diaconu, C. Cristea, V. Harceaga, G. Marrazza, I. BerindeaNeagoe, and R. Sandulescu, "Electrochemical immunosensors in breast and ovarian cancer," Clinica Chimica Acta, vol. 425, pp. 128-138, 2013.

[20] J. Zhang, J. Wang, J. Zhu, J. Xu, H. Chen, and D. Xu, "An electrochemical impedimetric arrayed immunosensor based on indium tin oxide electrodes and silver-enhanced gold nanoparticles," Microchimica Acta, vol. 163, no. 1-2, pp. 63-70, 2008. 

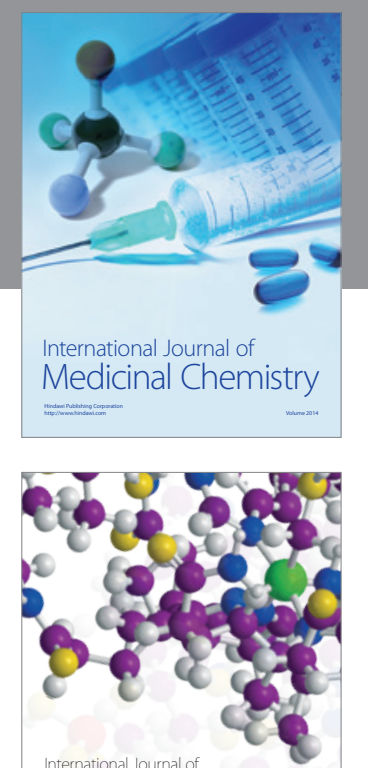

\section{Carbohydrate} Chemistry

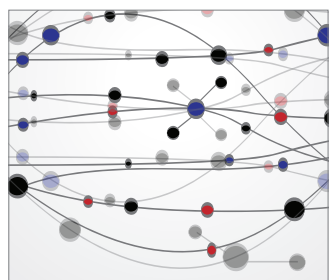

The Scientific World Journal
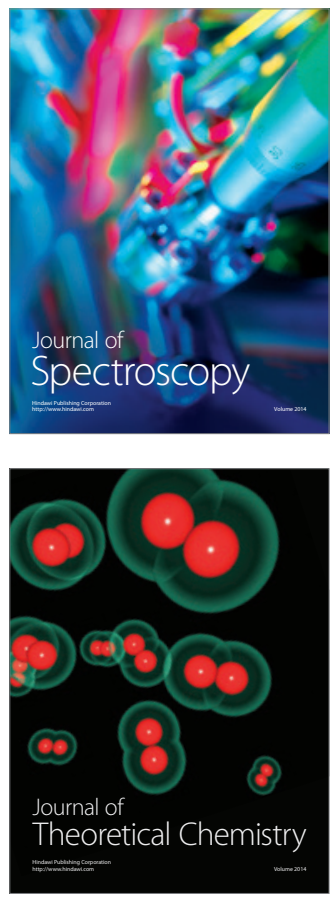
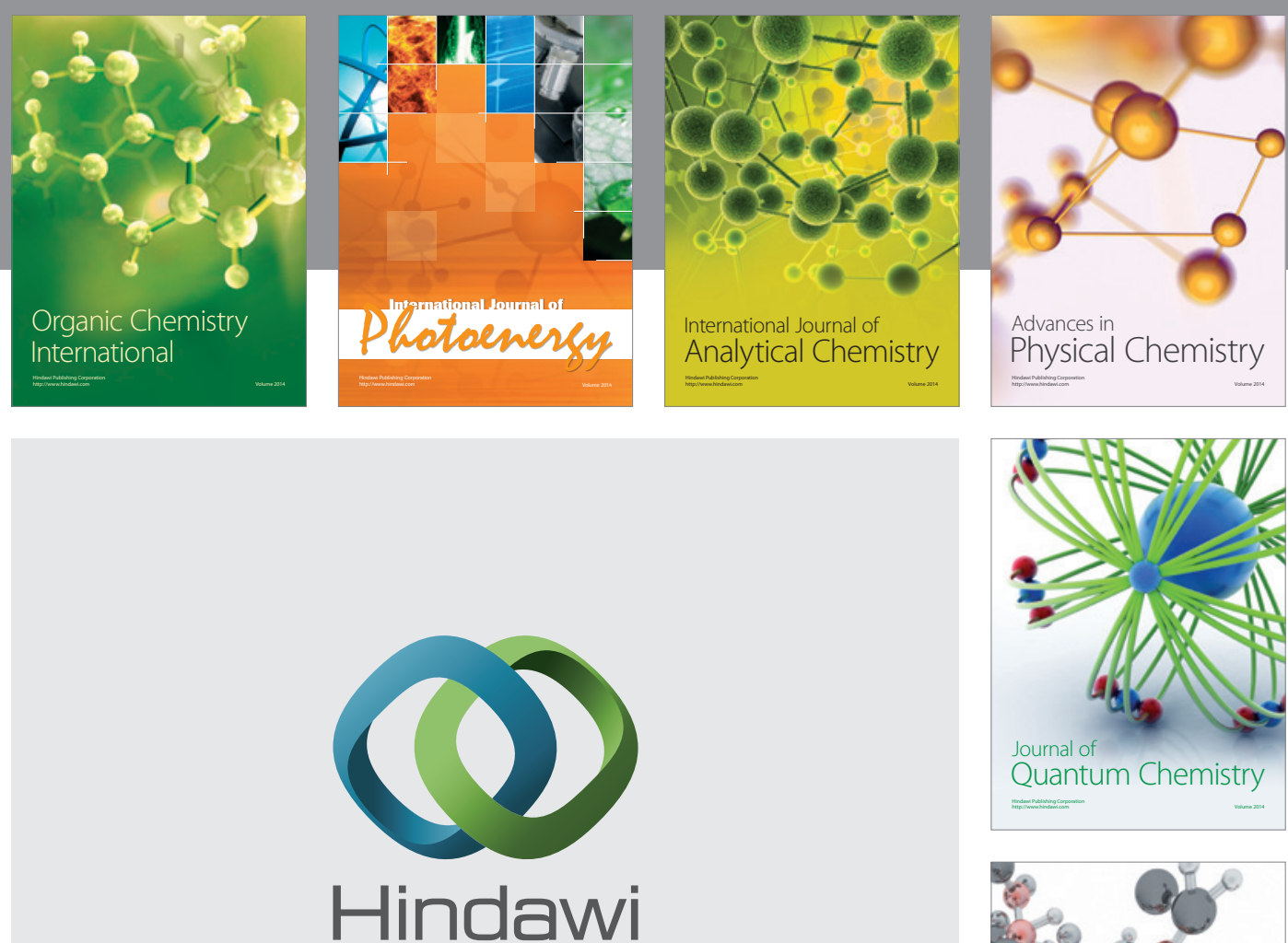

Submit your manuscripts at

http://www.hindawi.com

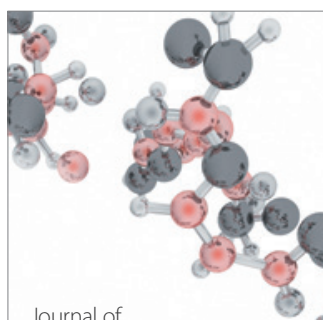

Analytical Methods

in Chemistry

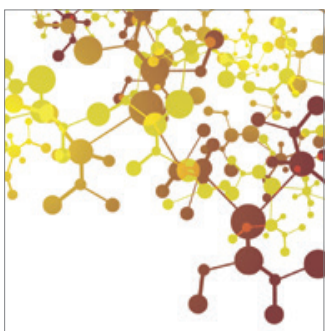

Journal of

Applied Chemistry

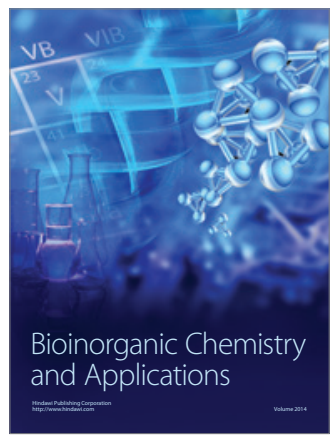

Inorganic Chemistry
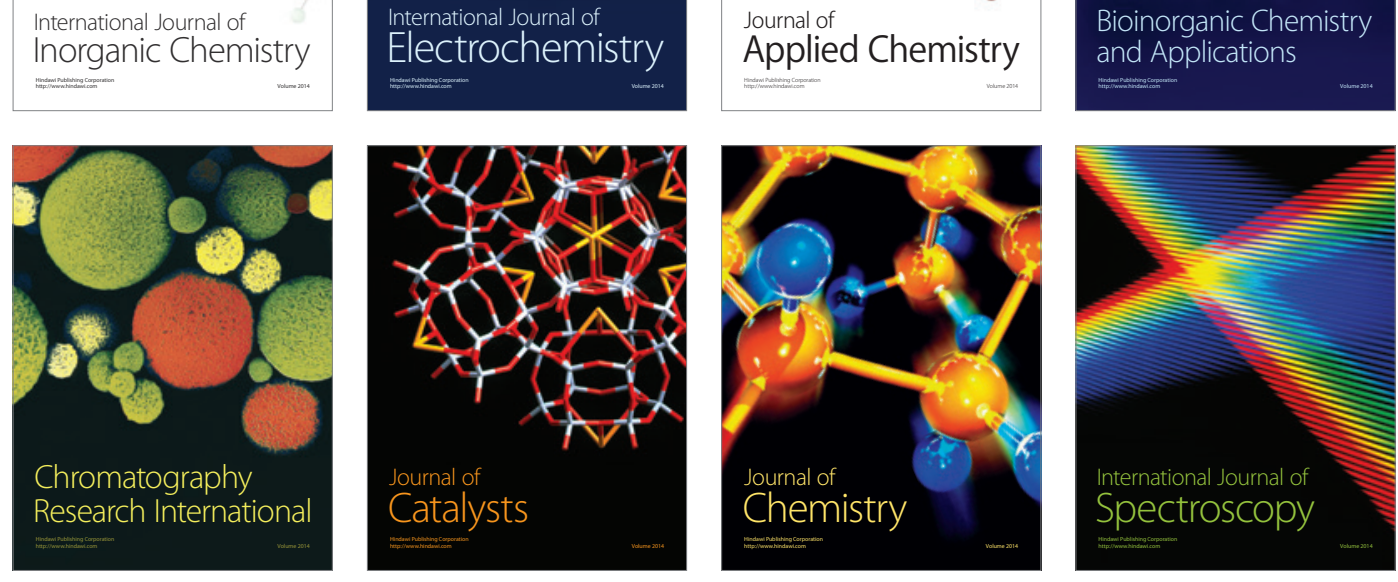